\title{
Letter to editor concerning: "Intradural lumbar disc herniation: report of five cases with literature review"
}

\author{
Angel Hidalgo-Ovejero $\cdot$ Serafin Garcia-Mata $\cdot$ Luis Barberena-Ayesa $\cdot$ \\ Norberto Zabalza-Hermoso de Mendoza • Miguel Menendez-Garcia • \\ Tomas Izco-Cabezon
}

Received: 21 October 2012/ Accepted: 16 December 2012/Published online: 27 February 2013

(C) Springer-Verlag Berlin Heidelberg 2013

\section{Dear Sir,}

We have a point we would like to make in reference to the article entitled "Intradural lumbar disc herniation: report of five cases with literature review", published by Ducati et al. [1] in European Spine Journal. Our attention was drawn to the fact that this author made no reference to a number of studies previously published by us [2,3] and other authors $[4,5]$ which mention the association of intradural herniations or cysts with gas within the spinal canal.

Moreover, we had already advised in our previous study of the possible need for intradural exploration where the CT or MRI imaging studies show the existence of gas within the canal and the intraoperative findings do not explain the patient's symptoms.

Conflict of interest None.

\section{References}

1. Ducati LG, Silva MV, Brandão MM, Romero FR, Zanini MA (2012) Intradural lumbar disc herniation: report of five cases with literature review. Eur Spine J (Epub ahead of print)

2. Hidalgo-Ovejero AM, Garcia-Mata S, Izco-Cabezon T, GarraldaGalarza G, Martinez-Grande M (1998) Intradural disc herniation associated with epidural gas. Spine 23:281-283

3. Hidalgo-Ovejero AM, Martinez-Grande M, Garcia-Mata S (1994) Disc herniation with gas. Spine 19:2210-2212

4. Chiu LJ, Tsai PC, Chou PC, Kuo TM, Cheng C, Li MJ, Lin TY, Yip BS (2008) A gas filled intradural cyst with intradural disc herniation: a case report. Acta Neurologica Taiwanica 17:36-41

5. Kudo Y, Nishijima Y, Mochida K, Sekido Y, Tachibana S (2008) Gas-filled intradural cyst with migration into the nerve root of the cauda equina. J Neurosurg Spine 8:482-486. doi:10.3171/SPI/ 2008/8/5/482

A. Hidalgo-Ovejero $(\bowtie) \cdot$ S. Garcia-Mata .

L. Barberena-Ayesa - N. Z.-H. de Mendoza .

M. Menendez-Garcia · T. Izco-Cabezon

Department of Orthopedics, Complejo Hospitalario de Navarra,

Avda Pio XII 16 Esc Dcha $3^{\circ}$ C, 31008 Pamplona, Spain

e-mail: angehidalgo@ya.com 